\title{
The Mental Health Workshop in the Human Rights Convention
}

\author{
Walid Abdul-Hamid
}

\begin{abstract}
Between the 15 and 17 of June 1995, Liberty and other orgonlsations concerned with human riohts coordinated the Human Rights Convention. This gothering examined the meaning of humen ilghts, why they matter, and how they could be strengthened. In the full programme there was a workshop on mental health. This workshop examined how mental health legtslation and practices offect the human rights of poychiaticic sonvice users.
\end{abstract}

The workshop was attended by both users and professionals of mental health services, but psychiatry was underrepresented. The workshop was facilitated by Peter Campbell who is a member of the users' organisation 'Survivors Speak Out' and Camilla Parker from the Legal Section of MIND.

The current use of the Mental Health Act of 1983 was examined and examples were given of appropriate and inappropriate use of the sections of this act. Concern was expressed that the act does not give enough weight to the opinion of the user's general practitioner (GP). It was reported that frequently when GPs do not agree with the compulsory admission of their patients, the admitting hospital invites a second opinion psychiatrist who usually overrides GPs' opinion and signs the section. Another problem with the 1983 act is the lack of advocacy for patients detained under the act. Approved social workers are trained to fulfil this role, but their lack of experience with mental health often makes them unable to oppose the medical opinion.

Other problems with the implementation of the act were mentioned. For example, the discrimination experienced by people from ethnic minorities, the abuse of women detained on mixed wards and the difficulty in accessing a lawyer in the process of appealing to mental health tribunals.

The discussion flowed from compulsory admission to compulsory treatment. MIND expresses reservations about the practices associated with giving electroconvulsive therapy (ECT). A recent study showed that $90 \%$ of second opinion doctors agreed with the treating doctor on giving ECT to the patients (Fennell, 1995). On the other hand, a study was quoted reporting that only $40 \%$ of patients receiving ECT were given enough information (Rogers et al, 1993). It was commented that the psychiatric profession ignores the 'spiritual significance' of recetving electric shocks to the brain which in the public mind is associated with Frankenstein and horror stories.

The controversial issues regarding drug treatment in psychiatry were explored. It was suggested that psychiatrists often ignored patients' views and complaints about medication. MIND has proposed the use of 'advanced directive' by patients when they are well. They can state in it what treatments they would or would not like to recelve when they become ill. Furthermore. MIND has issued a special yellow card for patients to report any side-effects and adverse reactions experienced by them after taking psychiatric medication. This card is to be sent to MIND where these side-effects will be monitored and reported.

Lastly the workshop discussed the newly proposed mental health (community) bill. MIND expressed their strong reservations regarding the new power of 'after care under supervision'. According to MIND the grounds of this bill are too vague, patients' rights and involvement in decisions regarding their care are minimal. In addition there are no extra resources provided for implementing the bill which might result in over reliance on medication and restraint.

There is a large gap in understanding of the above mentioned issues between psychiatrists and the users. There is also a need for a closer link between the Royal College of Psychiatrists and users' organisations such as MIND. This could be achieved by organising joint meetings between the College and users' organisations to share views and reach common grounds of understanding.

\section{References}

FEnNEu, P. (1995) Treatment Without Consent, Law, Psychiatry and the Treatment of Mentally III People Since 1845. London: Routledge.

Rogers, A., PILGRM, D. \& LACEY, R. (1993) Experlencing Psychiatry, User's Views of Services. London: MIND.

Walid Abdul-Hamid, Senior Registrar, Portnalls Unit, Farnborough Hospital, Kent 